\title{
Do Oral and Literacy Skills in Native Ghanaian Akan Language Modulate English Reading Comprehension as Second Language?
}

\section{A Study in Selected Basic Schools in Ghana}

\author{
Stephen Ntim (PhD; M. Phil; M.A; B. Ed) \\ Faculty of Education \\ Catholic University of Ghana, \\ P.O. BOX 363, Sunyani, Fiapre, B/A Ghana \\ E-mail: stephenntim58@yahoo.com; stephen.ntim@cug.edu.gh
}

Received: January 24, 2016 Accepted: June 12, 2016 Published: June 14, 2016

doi:10.5296/elr.v2i2.8867ＵRL: http://dx.doi.org/10.5296/elr.v2i2.8867

\begin{abstract}
This study investigated oral and literacy skills in native Ghanaian Akan language in mediating English reading comprehension of bilingual basic school students. Levene's test for homogeneity of variance between groups on questions directly found in text showed variances were significantly different $[\mathrm{F}=49.070, \mathrm{p}=0.00]$. Bonferroni Post-hoc test comparing groups on questions requiring making multiple sentence meanings to be able to answer, data indicated a significant difference between mean scores of students who speak both English and Akan and students who speak English Only in favour of students who speak both English and Akan. Also, students who speak Akan Only performed significantly better than students who speak English Only with.no significant difference between mean scores of students who speak Akan Only and students who speak both English and Akan. This suggests the impact of native language in second language reading comprehension is enormous. When bilinguals are reading second language (and in this study English) they are likely to make use of previous knowledge, strategies and processes from the first language through cognitive/psycholinguistic factors as orthographic processing, phonological code and meaning activation among others and by so doing limiting the effect of cognitive load in the target language.
\end{abstract}

Keywords: Native language, Second language, Reading comprehension 


\section{Introduction}

Vygotsky in the mid 1980's made the submission that language is the most powerful tool in the development of any human being. It separates humans from their biologically closest ally such as the Chimpanzee. A firm grasp of language facilitates one's ability to reason since language and 'thought' are inseparable' (Vygotsky, 1986). In this respect, the first six years are deemed to be crucial for children as they develop their first (native) language as well as their cultural identity. In these foundational years of their growth and development, children construct their experience and knowledge of the world around them. With respect to children from other linguistic backgrounds than English, the native language used since birth is fundamental. It constitutes the foundation for developing meaningful communication and relationships with adults and peer and such interactions form the key to language acquisition (Siraj-Blatchford \& Clarke, 2000).

Evidence indicates that young children are capable of learning multiple languages with ease, when exposed to good language models and have considerable exposure to both languages. Therefore, maintaining the native (first) language indeed does not constitute psychological interference with the learning of English or any other second language (Clarke \& Milne, 1996). Research suggests rather the opposite - that knowing one's native language facilitates children's understanding of how other languages work for three reasons: a) it enhances positive self-concept and well-being of children; b) children who maintain first language are likely to transfer cognitive development, when learning other second language; c) children's level of competence in the second language is likely to be related to level of competence already acquired in the first language, helping them to transfer skills from one language to another (Cummins, 1984). Benefits of bilingualism have consequently been identified as extremely crucial to providing a solid impetus for learning a second language (Cummins 1984; Clarke \& Milne 1996).

The local language policy as it exists in Ghana now is that pupils from kindergarten one through to primary three are required to be instructed in the local languages. Mother tongue, as medium of instruction in Ghanaian basic schools, was strengthened by the 1925 Education Ordinance during the British colonial rule. Ghanaian languages as medium of instruction became compulsory from primary one to three and as subject of study at primary four. English Language was used from primary four and above. This was the arrangement until, after political independence in March 1957, mother-tongue as medium of instruction at the lower primary was changed.

\section{Statement of Problem}

Studies suggest that enhancing learning and education in Sub-Sahara Africa is largely language-related. Research in many African schools indicates that learners with below average ability in English as second language are more likely to have learning problems than those with average ability (Macdonald, 1993; Rubagumya, 2003). Mother tongue medium education (MTE) on the other hand has been identified as helping teachers to teach more effectively and students to learn with ease especially at the elementary level of education (Heugh, 2006). Given the fact that UNSECO global report showed global learning deficiency of nearly two hundred and fifty million $(250,000,000)$ children of school age in Africa lacking reading and writing skills, whether they are in school or out of school 
(http://www.unesco.org), psychology, education and language researchers cannot refuse to find out the early precursors of this linguistic deficiency.In Ghana, reports from the Ministry of Education in 2008 (MOE: 2008) as well as reports from the Chief Examiner of the Basic Education Certificate Examination (BECE) identify reading deficiency in English (as a second language) as a fundamental bane. It is estimated that nearly fifty percent $(50 \%)$ of young women and one-third of young men could hardly read a sentence in English, after they had spent six years in the primary school (Ghartey, 2010).

Consequently, in the context of available research data in Ghana and in many African nations showing learning deficits with literacy skills especially with reading in English language, there is the justification to find out whether or not the use of native Ghanaian Akan language in the homes of Junior High School (JHS) pupils contributes to enhancing English reading proficiency as second language or is indeed an interference.

Besides, given the increasing trend in Ghana and in many other African countries to expose children from urban educated families to foreign languages (English, French, Portuguese) at the expense of children's native languages, the objective of this study is to find out whether or not, native language is indeed a hindrance or a resource in children's reading comprehension in their second language. Even though, language policy as it stands in Ghana, Akan is taught basic schools in all Akan-speaking area. Most children interact with other adults in Akan. Nevertheless, the over-all emphasis in English by many educated Ghanaians overrides the native Akan language, such that many Ghanaian children from Akan and other local speaking areas can hardly write and speak better Akan or any of the other local languages. Besides, language policy as medium of instruction keeps moving back and forth in Ghana since political independence from British colonial rule

\section{Research Questions}

Based on the above defined problem, this research paper attempted to seek some answers to the following two (2) research questions:

1) Does children's first or home language any role in shaping their English reading comprehension?

2) What effects does the continued development of first or home language have on children's knowledge and competencies in English reading comprehension?

\section{Literature Review/Theoretical Perspective}

\subsection{The Contrastive and the Error Analyses approaches}

Two significant approaches have been used in the literature to assess the impact of first (native) language in the learning of a second language: the Contrastive Analysis (CA) and the Error analysis (EA). The behaviorist view of learning, underpinned by the interaction between stimulus and response for years provided the psychological basis for the Contrastive Analysis on the impact of native language in the learning of a second language. The core assumption of this view is this: human behavior was assumed to be the aggregate of its components, and language learning to be the acquisition of all these elements (Hosni Mostafa El-dali, 2011). Similarly, the structural approach also provided the theoretical basis for the Constrastive Analysis with the assumption that comparing the two languages would help identify contrasts between them. It is in this respect that Hosni Mostafa El-dali (2011) citing 
Dulay and Burt (1972) sums up the theoretical underpinning of Contrastive Analysis in the following two ways: (a) language learning is habit formation, (b) where L2 and L1 differ, the old habit (using L1) hinders the formation of new habit (learning L2).

\section{2 Predictive Versus Explanatory and Apriori Versus Aposteriori Approaches}

The 1970's saw two versions of the Constrative Analysis: the 'predictive vs. explanatory' proposed by Wardhaugh and 'apriori vs. aposteriori by Gradman (1971). The fundamental idea behind the former approach is that one can contrast the system of one language with that of a second language. Based on the results of this contrast, researchers can identify similarities and dissimilarities between native and second languages. Consequently, inferential predictions regarding possible difficulties for the learner of other languages could be made. The implicit assumption here is this: similarities are more likely to be learned with ease than with dissimilarities. This approach suggests some linguistic universals within the framework of a comprehensive linguistic theory dealing with issues such as syntax, semantics and phonology (Wardhaugh, 1970). The error analysis approach to the influence native language on the learning of a second has been derived from two core assumptions: a) that linguistic error analysis would help researchers to underscore the possible errors; b) that researchers may realize the potential difficulty of identified errors based on the frequency of their occurrence (Schacter, 1974).

As submitted by Dulay, Burt and Krashen (1982), the validity of the Contrastive Analysis appears to be more predictive at the phonological level but less reliable at the syntactic level. Thus, research results suggest that the main impact that native language (L1) has on the learning of a second language (L2) is more on accent rather than on grammar and syntax.The view of many scholars is that it is this phonological differences in the native language that come to the fore in the way for example, a Ghanaian-born child in Ghana would speak English differently from the way a Ghanaian-American child, born and bred in the US or in England would speak the same language. These phonological differences may be explained, primarily to the structure of the L1 phonology and, in the second case, to dialectal differences. It is in this respect that one can say that mispronunciation on the part of L2 learners may be traced back, to linguistic transfer, i.e., LI interference (Conley, 2008; Han, 2005; Jiang, 2007; Hoey, 2007; Kimberly, 2009).

This Contrastive Analysis approach of the influence of native language in the learning of a second language, however, has been disputed on theoretical grounds for some four decades now. Stockwell and collaborators (1965) using two verbs in Spanish 'conocer' and 'saber' which both means 'to know' in English explains that they correspond to different senses of the English verb 'to know'. This lexical difference is likely to pose difficulties for English speakers learning Spanish whereas .it would be less so for Spanish speakers' learning English. Similarly, Pica (1984), also maintains that the divergent areas between the learner's LI and the target language however do not represent the greatest learning difficulties. The difficulty, rather, may be accounted for due to areas sharing similarity rather than dissimilarity. In short, some scholars claim that, the Contrastive Analysis (CA) does not seem to offer a plausible explanation of the influence of native language in the learning of a second language

The Error Analysis (EA) approach on the other hand as submitted by Brown (1988) perceives frequency of errors as proportional to the degree of learning difficulty. This approach 
accounting for errors the learner brings to the target language could not be predicted by CA analysis. This error analysis has also been disputed. For example, Celce- Murcia (1977) criticized the difficulty of certainty about exact errors a second-language learner is likely to make because underlying reasons are multi-factorial such as the phenomenon of intralingual transfer or negative transfer within the target language. Early stages of language learning are more likely to be influenced largely by what Taylor (1975) characterized as intralingual transfer' but when learners gradually acquire part of the new system, generalization within the target language is manifested. In defining 'intralingual errors,' some scholars characterize them into the following errors: a) errors attributable to incomplete application of rules; $b$ ) errors attributable to over- generalization or the creation of ill-formed structures based on the speaker's knowledge of the other structures in the second language; and c) errors attributable to failure to learn the conditions under which rules apply (Richards, 1971;Hosni Mostafa El-dali, 2011).

\subsection{Language Transfer and Markedness}

The concept of 'markedness' in linguistic studies goes back to the Prague School. In its genetic usage it refers to feature differences in phonology between first/native language (L1) and a second language (L2) or vice versa in which one contains a feature that the other does not have. The phoneme carrying the feature was the 'marked; the other unmarked. Research works focusing on second language in the 1980'ssuch as Kellerman (1983) used this term to predict when transfer to the second language was likely to occur from the native/first language Structures in the learners L1 deemed to be irregular, infrequent and semantically opaque were considered less transferable into the second language. Features from first language considered unmarked are thought to be less complex than marked. Kellerman (1983) reported that learners transfer both marked and unmarked features from their LI initially, but that in the more advanced interlanguage, they avoid transferring marked features. Chomsky sees the rules of core grammar (aspects of the language that have become part of the child through the interaction of the Universal Grammar with the relevant language environment) as unmarked while peripheral grammar are marked. Peripheral grammar in linguistic literature constitute elements in language that is not constrained by Universal Grammar, but derived, nevertheless, from the history of the language borrowed from other languages. In this sense, rules of the core grammar are seen to be easier to set than are rules of the peripheral grammar, thought to be outside of the child's already programmed instructions.

\subsection{Inter-language Framework}

Selinker (1972) was the first researcher to come up with the term 'inter-language'. It is the interim grammars constructed by second-language learners as they move to the target language. This became a more popular term than similar other terms by Nemser (1971) and Corde (1967) as 'approximative system' and 'transitional competence' respectively. Generally, , the term 'interlanguage' in linguistic studies signifies two things: a) the learner's system at a single point in time, and (b) the range of interlocking systems that characterize the development of learners over time. This concept is assumed to be distinct from the learners' native language and from the second language. This is thought to be so because this gradually evolves over time as learners make use of various internal strategies to make meaning of the stimulus to control their response to the learning of the second language. 
Selinker (1972) describes five cognitive processes involved in the learning of a second language from the perspective of interlanguage: a) language transfer from $L(1)$;b) transfer of the training process used to teach the second language; c) strategies of second-language learning; d) strategies of second - language communication; and e) overgeneralization of the target language linguistic material. This position of Selinker (1972) has been contested by Adjemian (1976). The latter's position is that rather the systematicity of inter-language needs to be analyzed linguistically as rule-governed. This implies that the learner's first language system is perceived to be stable whereas inter-language is not.

\subsection{Native Language as Basis for Oral Language and Literacy Development}

Using one's native language builds a link between the home and school and so it is beneficial when families are encouraged to read and talk to children in the family's native language since this lays a foundation for linguistic ability that is not only capable of advancing the learning of their first language, but it also enhances the learning of a second language such as English, in both academic and social situations. Thus, incorporating the native language to the second language learning process helps young children associate reading and writing with meaning and literacy from their home. In other words, when there is a solid foundation in the native language, it already predisposes children to syllabic and phonemic acquisition which paves the way for reading and writing in a second language (cf. http://www.tesol.org).

Snow, Burns and Griffin (1998) make the claim that academic progression and graduation in is contingent with reasonable proficiency in reading skill at the end of grade 3 . The implication is this: improving literacy skills, especially reading progammes in the early childhood and primary classrooms is pivotal to ensuring reading mastery by the third grade. Research findings suggest that children from linguistic background other than English, such as basic pupils in Ghana, who need English to function in school, their native language can support language and literacy development. This is because every child enters the school with a certain level of basic foundational knowledge and learning from the home especially the first language. This first/native language therefore constitutes the basis for children to begin constructing knowledge and to make meaning out of their relationships. Thus, language and literacy proficiency in one's first language forms the bedrock for a new language (Cummins, 1991; Paez \&Rinaldi, 2006; Proctor, August, Carlo, \& Snow, 2006).

\section{Current Study}

The point of convergence between these various models of linguistic studies reviewed above, notwithstanding the respective theoretical counter positions, can be summed up in the following two conclusions: a) children with firm grasp of native language are more likely to transfer background knowledge, strategies and processes from the native language to the leaning of a second language than those with little or fragmentary knowledge of their own first language; b), languages differ in their respective details, nevertheless, there seems to be a universal grammar underlying all languages. This makes it easier for children with foundation in their native language, to learn a second language with a certain level of ease. This linguistic universal in the context of a comprehensive linguistic theory of Wardhaugh (1970), as well as the error analysis linguistic theory, constitutes the theoretical framework of this research paper. Based on this framework, this current paper investigated whether or not oral and literacy skills in native Akan language in Ghana are hindrance or resource in English 
(as a second language). Based on contemporary reports in Ghana from the Ministry of Education in 2008 (MOE: 2008), as well as the abysmal performance of considerable number of Ghanaian basic school pupils in the School Education Assessment (SEA) Examinations in July 2006 and in 2008, the findings of this study would be significant to stakeholders such as educationists, basic school teachers, educational psychologists, psycholinguistics, linguists, parents, the Ghana Educational Service (GES) etc. The findings therefore will help to throw more light as to whether or not proficiency in native language impedes or aids the efficient learning of other language(s) apart from contributing to the already existing literature in education and linguistic research.

\section{Research Methodology}

\subsection{Sample and Design}

This study tested whether or not oral and literacy skills in native Akan can mediate English reading comprehension for Ghanaian Junior High School students who use English as second language in four (4) administrative regions of Ghana. The aim was to test the Ghanaian perception that frequent use of local language in the homes could undermine children's grasp of English. Language policy as it exists now in Ghana is that pupils from kindergarten one through to primary three now are instructed in local languages. Beyond this level, English is the medium of instruction. Besides school instruction in native language, most parents in the homes simply refrain from using local languages. A purposive, random sampling size of three hundred (300) pupils, aged between 12 and 15 from the same socio-economic parental home backgrounds were selected. They were in three (3) groups in which: a) English was the principal medium of communication between children and parents without Akan (English Only); b) homes that both English and Akan were used intermittently as medium of communication between children and parents (English and Akan); and c) homes in which Akan was used as the only medium of communication (Akan Only). All children tested in this experiment were normal developing children who were native speakers of Akan (specifically Asante Twi) with English as a second language. One hundred and fifty (150) were males and the other one hundred (150) were females. Twenty-five percent came from single-parenting homes and the other seventy-five percent came from two-parent family background.

\subsection{Procedure and Measures}

These selected Ghanaian students were tested in their school locations during the months of May and June, 2015. Ninety multiple choice questions adapted from the comprehension section of the Gates-MacGinitie reading test (GMRT) grade level 7-9 was used as instrument to test their comprehension in selected English texts. They were tested along the following two main variables/tasks: a) verbatim, b) transformed paraphrase. For example in verbatim, these were questions directly found in the text; and in transformed paraphrase, these were questions that required making multiple sentence meanings to be able to answer. For example: in the sentence: 'my friend is too rich to be my consort'. The transformation of this sentence containing the adverb 'too', can take place without changing the meaning of the sentence as in: 'my friend is so rich that he cannot be my consort'. Similarly, the sentence: 'the news is too good to be true' can be transformed and paraphrased as: 'the news is so good that it cannot be true' without any change in meaning. The purpose of this test was to test the two research questions in this study: a) Does maintaining children's first or home language any 
significant role in shaping English reading comprehension? and b) What effects does the continued development of first or home language have on children's opportunities to build on knowledge and competencies in English reading comprehension?

\section{Experiment 1}

This first experiment tested the students on English reading comprehension with specific reference to item difficulty as function of matching between stem and passage on verbatim, as explained above. The purpose was to test the three groups: A, B, C whether or not there is any statistically significant difference in their reading comprehension of questions directly found in the reading of a text. The hypothesis being tested here is that all things being equal, those students exposed to the use of 'English Only' (without Akan) should perform significantly better in the above named comprehension variables than the other two groups.

\section{Results}

Table 1. Scores on Verbatim

\begin{tabular}{llll}
\hline Language used by students & $\mathrm{N}$ & Mean & Standard deviation \\
\hline English only & 100 & 56.06 & 9.631 \\
English with Akan & 100 & 51.27 & 2.206 \\
Akan only & 100 & 52.58 & 11.557 \\
\hline
\end{tabular}

Table 2. Test of Homogeneity of Variances on Verbatim

\begin{tabular}{lllll}
\hline & Levene's statistic & df1 & df2 & Sig \\
\hline Verbatim & 49.070 & 2 & 297 & 0.000 \\
\hline
\end{tabular}

Table 3. ANOVA TEST on the scores on Verbatim

\begin{tabular}{lllllll}
\hline & Sum of Squares & Df & Mean Square & F & Sig. \\
\hline Verbatim & Between Groups & 1225.687 & 2 & 612.843 & 7.952 & 0.000 \\
& Within Groups & 22887.710 & 297 & 77.063 & & \\
& Total & 24113.397 & 299 & & & \\
\hline
\end{tabular}

Table 4. POST- HOC Test on Verbatim

\begin{tabular}{|c|c|c|c|c|c|}
\hline Dependent Variable & $\begin{array}{l}\text { (I)language } \\
\text { commonly used } \\
\text { students }\end{array}$ & $\begin{array}{l}\text { (J)language } \\
\text { by commonly used } \\
\text { students }\end{array}$ & $\begin{array}{l}\text { Mean } \\
\text { by Difference } \\
(\mathrm{I}-\mathrm{J})\end{array}$ & $\begin{array}{l}\text { Std. } \\
\text { Error }\end{array}$ & Sig. \\
\hline \multirow[t]{4}{*}{ Games-Howell } & English only & English with Akan & $4.790^{*}$ & 0.988 & 0.000 \\
\hline & & Akan only & 3.480 & 1.504 & 0.056 \\
\hline & Akan only & & & & \\
\hline & & English with Akan & 1.310 & 1.177 & 0.508 \\
\hline
\end{tabular}

*. The mean difference is significant at the 0.05 level. 


\section{MInstitute Macrothink $_{\text {Int }}$}

The descriptive statistics as in Table 1, shows that the students who use 'English Only'in the homes, had the highest score on Verbatim, followed by students who use Akan language Only and then students who use both English and Akan in that order. The means and standard deviations are as follows: $\mathrm{M}=56.06, \mathrm{SD}=9.631 ; \mathrm{M}=51.27, \mathrm{SD}=2.206 ; \mathrm{M}=52.580, \mathrm{SD}=11.557$ for 'English Only', 'English and Akan', and 'Akan Only' respectively. The huge mean with lower standard deviation as in the case of English and Akan suggest performance was good and closely related. All students performed well on the test. The high mean with high standard deviation as in 'Akan only' suggests there were outlets: some students performed very well while others preformed lower.

To find out whether their variances were statistically different, Levene's test for homogeneity of variance was used and the results as in Table 2 shows their variances were significantly different $[\mathrm{F}=49.070, \mathrm{p}=0.00]$. Analysis of Variance was used to compare the means scores of the three groups on Verbatim. The results as in Table 3, reveal that at an alpha level of 5\% $(\alpha=0.05)$ the mean scores of the three groups were statistically different $[F=7.952, p=0.00]$.

Multiple comparisons of the three groups were more than using Games -Howell post-hoc test because the variances of the three groups were statistically different. The result as in Table 4 indicates that the mean scores for the students who speak 'English Only' and that of the students who speak both 'English and Akan' were significantly different. The mean score of the 'English Only' students was significantly higher than that of the students who speak both 'English and Akan'. However, there was no difference between the mean scores of the students who speak 'English Only' and the students who speak 'Akan Only'. Neither was there a difference between the mean scores of Akan Only students and both English and Akan students when it comes to answering questions directly as found in text.

In Table 1, three (3) interesting and rather surprising findings can be discerned from the statistical data above. First, even though, the score on the mean is higher for those students who speak 'English Only' in the homes as in Table 1, but the Leven's test for homogeneity shows variance to be significantly different. Secondly, comparing analysis of variance in the three scores on the same variable of 'verbatim' also indicates significant differences. Thirdly, multiple comparison of the three groups through Games-Howell post hoc test indicate a rather surprising finding of no difference between the means scores of 'English Only' and 'Akan Only' and 'Akan Only' and 'English and Akan'. An interesting finding here is that even though, the mean score seem higher with the first group ('English Only') but the standard deviations show the scores of the 'Akan Only' were more spread about the means while that of 'English and Akan' were the least spread.

The descriptive statistics in Table 4 indicate that there was no difference between the mean scores of the students who speak 'English Only' and the students who speak 'Akan Only'. Neither was there a difference between the mean scores of Akan Only students and both English and Akan students when it comes to answering questions directly as found in text is striking. One would have expected 'English Only' speakers to have performed significantly better on this measure than the two other groups. This was not the case. This finding in the first experiment was interpreted as plausible mediating influence of oral and literacy proficiency in native Akan. This suggests that cognitively and psychologically, second language readers generally who have appreciable grasp of their native language appeared to 


\section{Macrothink}

have less challenges regarding automaticity of lower order comprehension processes. These processes became automatic and thus created space for faster cognitive processing. In so doing, cognitive load was lowered. They were therefore less constrained by overloaded working memories presented in the second language. Second language readers with less grasp of native language on the other hand, appeared to have been limited by excessive cognitive demands due to text elements they were unable to automatize. This corroborates the finding of Gorsuch and Taguchi (2008) that memory constraint in second language reading for those with little or less grasp of their first/native language often precipitates the inability to link available knowledge in memory with text in second language. In a more recent study, Moyra, (2013) demonstrates the impact of native language acquisition in facilitating the reading and comprehension of texts in the second language and this finding of the 'Akan Only' group seems to support this position. If the multiple comparisons of the three groups in Table 4 are anything to go by, as indicated in the first experiment above, one can plausibly make the submission that this confirms the position of Walter (2007) that L2 readers generally fail to access L1 higher order reading strategies. Consequently, they are not likely to perform well in comprehending language that is not their native language. This finding in this current study, however, contradicts Xiangying (2011) in which literacy in L1 was found to be less correlated with L2 proficiency. Nevertheless, it supports this same author's finding that L2 language proficiency did not indicate any significant correlation with L2 reading comprehension.

\section{Experiment 2}

This second experiment tested the same group as above on reading, this time with specific emphasis to test their comprehension ability to make transformed paraphrasing required to answer questions from a passage. Transformed paraphrase as used in this second experiment was this: these were questions that required making multiple sentence meanings to be able to answer. The purpose of this test was to assess the performance in English reading achievement between the three groups of students: A, B, and C.

\section{Results}

Table 5. Scores on Transformed Paraphrasing

\begin{tabular}{llll}
\hline Language used by students & $\mathrm{N}$ & Mean & Standard deviation \\
\hline A: English only & 100 & 50.50 & 12.268 \\
B: English with Akan & 100 & 55.80 & 11.948 \\
C: Akan only & 100 & 55.00 & 12.745 \\
\hline
\end{tabular}

Table 6. Test of Homogeneity of Variances

\begin{tabular}{lllll}
\hline & Levene's statistic & df1 & df2 & Sig \\
\hline Transformed Paraphrase & 0.232 & 2 & 297 & 0.793 \\
\hline
\end{tabular}


Table 7. ANOVA Test on Scores on Transformed Paraphrasing

\begin{tabular}{lllllll}
\hline & & Sum of Squares & Df & Mean Square & F & Sig. \\
\hline Transformed & Between & 1632.667 & 2 & 816.333 & 5.374 & 0.005 \\
Paraphrase & Groups & & & & & \\
& Within Groups & 45113.000 & 297 & 151.896 & & \\
& Total & 46745.667 & 299 & & & \\
\hline
\end{tabular}

Table 8. POST-HOC on Scores on Transformed Paraphrasing

\begin{tabular}{llllll}
\hline $\begin{array}{l}\text { Dependent } \\
\text { Variable }\end{array}$ & $\begin{array}{l}\text { (I)language } \\
\text { commonly used by } \\
\text { students }\end{array}$ & $\begin{array}{l}\text { (J)language } \\
\text { commonly used by } \\
\text { students }\end{array}$ & $\begin{array}{l}\text { Mean } \\
\text { Difference } \\
(\mathrm{I}-\mathrm{J})\end{array}$ & $\begin{array}{l}\text { Std. } \\
\text { Error }\end{array}$ & Sig. \\
\hline $\begin{array}{l}\text { Transformed } \\
\text { Paraphrase }\end{array}$ & English only & English with Akan & $-5.300^{*}$ & 1.743 & 0.008 \\
& \multirow{2}{*}{ English with Akan } & Akan only & $-4.500^{*}$ & 1.743 & 0.031 \\
& \multirow{2}{*}{ Akan only } & English only & $5.300^{*}$ & 1.743 & 0.008 \\
& & Akan only & .800 & 1.743 & 1.000 \\
& English only & $4.500^{*}$ & 1.743 & 0.031 \\
& English with Akan & -.800 & 1.743 & 1.000 \\
\hline
\end{tabular}

*. The mean difference is significant at the 0.05 level.

Students were again tested on Transformed Paraphrasing the results are presented in Table 5 to Table 8 . The result in Table 5 shows that students who speak 'English Only' had a mean score of $[\mathrm{M}=50.50, \mathrm{SD}=12.268]$, students who speak both 'English and Akan' had a mean of $[\mathrm{M}=55.80, \mathrm{SD}=11.948]$ and the mean score of the students who speak 'Akan Only' was $[\mathrm{M}=55.00, \mathrm{SD}=12.745]$. The students who speak both English and Akan scored higher than the other two groups.

The test of homogeneity of variance as shown in Table 6 indicates that the variances of the three groups were not statistically significantly different $[\mathrm{F}=0.232, \mathrm{p}=0.793]$. ANOVA test on the mean scores of the three groups on transformed paraphrasing (Table 7)) shows that the performance of the three groups on this variable was statistically different $[F=5.374$, $\mathrm{p}=0.005]$. Because the variances were not significantly different, Bonferroni Post-hoc test was done to compare the three groups on 'Transformed paraphrasing'. The result as in Table 8 shows that: there is a significant difference between the mean scores of students who speak both English and Akan and the students who speak English Only in favour of the students who speak both English and Akan. Also, students who speak Akan Only performed significantly better than students who speak English Only. There was no significant difference between the mean scores of students who speak Akan Only and students who speak both English and Akan.

The findings in the second experiment were interpreted by this author to mean that the acquisition of practical and social language in a second language is not synonymous with 
acquisition of academic language skills. While it may be easier for Ghanaian children who speak 'English Only' in their homes to acquire sufficient skills in English, this was not sufficient reason that they would be equally good in comprehending the same L2 as academic language. Thus, as level of difficulty moves from 'verbatim' ( directly asked questions from text) towards 'transformed paraphrase', in which questions required making multiple meanings, to be able to answer questions in text comprehension, students with firm grasp of native Akan language appear to be better comprehenders than those with little or less understanding of their native Akan.

This corroborates the submission of Cummins (1984) that we need to distinguish between social use of language and academic use of language. As children progress through the academic ladder, those with a solid knowledge of their first language are able to transfer skills from one language to another. Cummins (ibid) makes the distinction between two differing kinds of language proficiency. BICS are 'Basic Interpersonal Communication Skills'; these according to him are the "surface" skills of listening and speaking typically acquired very fast by many students; particularly by those from linguistic and home backgrounds where English is the only speaking language. CALP is 'Cognitive Academic Language Proficiency', and, as implied by the name, it is the foundation for children's ability to cope with the academic demands placed upon them in the various subjects. Cummins explains that while many children develop native speaker fluency (i.e. BICS) within two years of immersion in the target language, it takes between 5-7 years for a child to be working on a level with native speakers as far as academic language is concerned (http://esl.fis.edu/teachers/support/cummin.htm).

As indicated in this second experiment, consistently, either 'Akan Only' or 'English and Akan' groups performed almost as good as 'English Only' or even better than the 'English Only' group support the findings of Karim (2010), Durgunoglu \&Hancin-Bhatt(1992) and many others. Transfer of reading skills from native language seems to have overwhelmingly facilitative influence on L2 reading. It is in this instance that teachers, therefore, need to appreciate the advantage of L2 learners who have the skill to transfer previous linguistic knowledge, previous skills or existing schemata from their native language in order to facilitate their reading comprehension in the target language. This helps teachers to teach students strategic ways to use the second language more effectively. Most importantly, investigating and understanding reading transfer strategies facilitates a better understanding of the influence of first language knowledge in the reading and writing of a second language.

\section{Discussion}

The findings from the above two experiments suggest that improving the effectiveness of language learning, especially English as a second language in Ghana, one cannot ignore students (in this case pupils) native language. The data from this study, especially in the second experiment are clear: a) first the variances of the three groups were not statistically different in Table 6 on the homogeneity of variances; b) second in Table 8, one can see three (3) important findings: i) that there is a significant difference between the mean scores of students who speak both 'English and Akan' and the students who speak 'English Only' in favour of the students who speak both 'English and Akan'; ii) Also, students who speak 'Akan Only' performed just as good or better than students who speak 'English Only'; iii) 
that there was no significant difference between the mean scores of students who speak 'Akan Only' and students who speak both 'English and Akan'. Based on these important statistical indicators, the plausible inference could be made that, students who speak 'English Only' in their homes did not perform significantly better in second language (English) reading comprehension than those who speak 'Akan Only' or those who speak both English and Akan. Secondly at the level of verbatim, the mean score of 'English Only' was by far higher yet the variances in the standard deviations show that scores of this group were spread across the mean.

This positive transfer in favour of native Akan language in the case of 'Akan Only' and 'English and Akan' as against 'English Only' appear to support other psychological findings in which underlying cognitive/psycholinguistic factors, such as orthographic processing, phonological code and semantic activation from native language were able to positively transfer more than the English Only, might have accounted for minimizing the effect of cognitive load, imposed by the second language (cf. Karim 2010, Durgunoglu \& Hancin-Bhatt, 1992; Hornberger, 1990).

Consequently, on the basis of the data from the two experiments, the plausible hypothesis could be made, that when bilinguals are reading in their second language (L2), they usually bring to the act of comprehension, a background knowledge, strategies, and processes from their first language (LI). This in turn, facilitates their comprehension, notwithstanding the findings of other studies, that second language learning is more effective than the native language in enhancing reading comprehension of Language 2 (cf. Xiangying, 2011). Indeed, other studies indicate that the sole use of the target language (in this case English), leads to neglecting students' prior knowledge -especially with respect to strategy use. Hypothesis has been made that impoverished second language reading, is often the consequence of inconsistent use of students' first language reading strategies in the second language context. It is in this respect, that students' native language, can be seen as both a resource for teaching and learning, rather than as interference (cf. Harris, 2004).

These findings further corroborate other scientific studies that suggest that, for teachers to provide the needed appropriate learning opportunities, they have to make a conscious choice to include students' first language(s) in the classroom (Kobayashi, 2003). Research has shown that in addition to using students' first language, it also provides psychological benefits in helping to reduce cognitive demands. This is especially so, when students transfer reading comprehension strategies from the native language to the second language (Moore, 2006). For example, at the instructional level, understanding the nature of cross-language transfer in reading, contributes to helping language teachers to predict, not only the conditions under which a student will have difficulty when processing L2 (i.e. negative transfer), but also help teachers, to anticipate those conditions under which students are likely to show facilitation (i.e., positive transfer). Most children, generally, acquire language with little or no difficulty. However, acquiring reading comprehension calls for more effort and instruction. Notwithstanding the overlap, speech comprehension is different from written text comprehension (cf. Horowitz \& Samuels, 1987). When investigating the effects of L1on L2 acquisition, for most of the time, knowledge of the L1 is assumed to be well-developed. This appears to be corroborated in this paper in the case of those who spoke 'Akan Only' and those 
who spoke both 'Akan and English'. Thus, students are more likely to make use of previous strategies when studying in settings or with teachers who make conscious efforts to draw their attention to transferable strategies (Moore, 2006).

\section{Conclusion}

A grasp of native language appears to mediate second language reading comprehension rather than undermining it. It seems that when bilinguals are reading second language (and in this study English), they are likely to bring to the fore a great deal of prerequisite skills, previous knowledge, strategies as well as processes from the first language. This appears to be facilitated by cognitive/psycholinguistic factors, such as, orthographic processing, phonological code and meaning activation among others. Even though, most children acquire language with little or no difficulty, nevertheless, the findings from this study suggest that acquisition of reading skills in second language requires more effort and instruction. This implicates the fact, that, at the instructional level, understanding the nature of cross-language transfer in reading, can enable language teachers to predict those conditions likely to pose difficulty, when processing L2 (i.e. negative transfer), as well as the conditions under which a student will show facilitation (i.e., positive transfer).

The findings of this study, in addition to enhancing language teaching, also have implications for language policy formulation at the basic level of education. In Ghana, the use of mother tongue as a medium of instruction was strengthened by the 1925 Education Ordinance during the British colonial period. Ghanaian languages as medium of instruction were compulsory from primary one to three and as a subject of study at primary four, while English Language, was used from primary four onwards. This arrangement existed until 1957. Paradoxically, after political independence in March 1957, mother-tongue as medium of instruction at the lower primary was changed. English rather became the medium of instruction even from primary one. The Local Language Policy was revisited, switched off again and back. As it exists now, pupils from kindergarten one through to primary three now, are instructed in local languages. The findings of this study and many others, confirm this current language policy in Ghana, that when students and pupils at the basic level of their education, acquire firm grasp of their native language. They are more likely to transfer strategies and processes from native language, to perform better in literacy skills, such as, reading and English comprehension. The use of native language then in the early formative period of bilingual children is not an interference. Rather, it can be a resource in facilitating the learning of a second language.

\section{References}

Adjemian, C. (1976). On the nature of interlanguage system.Language Learning, 26, 297-320. http://dx.doi.org/10.1111/j.1467-1770.1976.tb00279.x

Brown, H. D. (1988). Principles of language learning and teaching. Englewood cliffs, NJ: Prentice -Hall, 1988.

Celce-Murcia, M. (1977). Memory, meaning and method: Some psychologist perspectives on learning language by Earl W. Stevick (review). Language, 53(2), 503-504. http://dx.doi.org/10.1353/lan.1977.0010

Clarke, P., \& Milne, R. (1996). Maintaining the first language and learning English as 
second language Talking diversity, free kindergarten association, children's services, Richmond, Victoria, Australia.

Conley, M. (2008). Cognitive strategy instruction for adolescents: What we know about the promise, what we don't about the potential. Harvard Education Review, 78(1), 84-106. http://dx.doi.org/10.17763/haer.78.1.j612282134673638

Corder, S. (1967).The significance of learner's errors.International Review of Applied Linguistics in Language Teaching, 5(4), 161-69. http://dx.doi.org/10.1515/iral.1967.5.1-4.161 Cummins, J. (1984). Bilingualism and special education: Issues in assessment and pedagogy, multilingual matters. UK. Department for Children, Schools and Families Early Years Foundation Stage, Department for Children, Schools and Families.

Cummins, J. (1991). Interdependence of first- and second-language proficiency in bilingual children. In E. Bialystok (Ed.), Language processing in bilingual children (pp. 70-89). Cambridge: Cambridge University Press. http://dx.doi.org/10.1017/CBO9780511620652.006 Dulay, H. C., \& Burt, M. (1972). Goofing: An indicator of children's second language strategies. Language Learning, 22(2), 235-252. http://dx.doi.org/10.1111/j.1467-1770.1972.tb00085.x

Dulay, H., Burt, M., \& Krashen, S. (1982). Language Two. Oxford University Press, New York.

Durgunoglu, A. Y., \& Hancin-Bhatt, B. J. (1992). The role of first language in the second language reading process. Technical Report No. 555, University of Illinois.

Ghartey, A. J. (2010). Quality basic education in Ghana: Prescription, praxis and problems. Paper Delivered at the Experience Sharing Seminar, 17-19 January 2010, Erata Hotel Accra.

Gorsuch, G., \& Taguchi, E. (2010). Developing reading fluency and comprehension using repeated reading Evidence form longitudinal students report. Language Teaching Research, 1, 27-59. http://dx.doi.org/10.1177/1362168809346494

Gradman, H. (971). The limitations of contrastive analysis predictions. PCCLLU Papers.

Han, Z. H. (2005). Input enhancement: Untangling the tangles. Keynote presentation at the 27th Winter Applied Linguistics Conference, New York State Teachers of English to Speakers of Other Languages, New York.

Harris, V. (2004). Cross-linguistic transfer of language learning strategies: Preliminary findings. Unpublished manuscript.

Heugh, K. (2006) Theory and practice - Language education models in Africa: Research, design, decision making, and outcomes. In H. Alidou et al. (Eds.), Optimizing learning and education in Africa - the language factor: A stock-taking research on mother tongue and bilingual education in Sub-Saharan Africa. Paris: ADEA.

Hoey, M. (2007). Grammatical creativity: A corpus perspective. In M. Hoey, M. Mahlberg, M. Stubbs, \& W. Teubert (Eds.). Text, discourse and corpora. London, Continuum.

Hornberger, N. H. (1990). Continua of biliteracy.Review of Educational Research, 59, 271-296. http://dx.doi.org/10.3102/00346543059003271

Horowitz, R., \& Samuels, S. J. (Eds.). (1987). Comprehending oral and written language. New York: Academic Press. 


\section{MInstitute Macrothin}

Hosni Mostafa El-dali, (2011). Re-examining the influence of native language and culture on L2 learning: A multidisciplinary perspectives. Humanicus, 6, 1-14.

Jiang, N. (2007). Selective integration of linguistic knowledge in adult second language learning.Language Learning, $57(1)$ $1-33$. http://dx.doi.org/10.1111/j.1467-9922.2007.00397.x

Karim, K. (2010). First language (L1) influence on second language (L2) reading: The role of transfer. Working Papers of the Linguistics Circle, 17, 49-54.

Kellerman, E. (1983). Now you see it, now you don't. In G. Sussan, \& L. Selinker (Eds.), Language transfer in language learning. Rowley, Mass: New bury House.

Kimberly, A. (2009). Adult learners perceptions of the incorporation of their L1 in foreign language teaching and learning. London: Oxford University Press.

Kobayashi, M. (2003). The role of peer support in ESL students' accomplishment of oral academic tasks.TheCanadian Modern Language Review, 59, 337-36. http://dx.doi.org/10.3138/cmlr.59.3.337

Macdonald, C. (1993). Towards a new primary curriculum in South Africa. Pretoria: Human Sciences Research Council.

MacGinitie, W. H., MacGinitie, R. K., Katherine, M., \& Dreyer L. G. (2004).Gates-MacGinitie Reading Tests 4th Edition (GMRT-4).

Moore, D. (2006). Plurilingualism and strategic competence in context. The International Journal of Multilingualism, 3, 125-138. http://dx.doi.org/10.1080/14790710608668392

Moyra, (2013). A case for using first language group discussions to facilitate second language reading comprehension retrieved 10th January, 2015, from http://www.ipedr.com/vol68/010-ICLLL2013-A00026.pdf

Nemser, W. (1971). Approximative systems of foreign language learners. International Review of Applied Linguistics in Language Teaching, 9(2), 115-124. http://dx.doi.org/10.1515/iral.1971.9.2.115

Páez, M., \& Rinaldi, C. (2006). Predicting English word reading skills for Spanish-speaking students in first grade.Topics in Language Disorders, 26, 338-350. http://dx.doi.org/10.1097/00011363-200610000-00006

Pica, T. (1984). L1 Transfer and L2 complexity as Factors in Syllabus Design. TESOL Quarterly, 18(4), 609-23. http://dx.doi.org/10.2307/3586583

Proctor, August, Carlo, \& Snow. (2006). The intriguing role of Spanish language vocabulary knowledge in predicting English reading comprehension. Journal of Educational Psychology, 98(1), 150-169. http://dx.doi.org/10.1037/0022-0663.98.1.159

Richards, J. A. (1971). Noncontrastive approach to error analysis. English language Teaching, 25, 204-19. http://dx.doi.org/10.1093/elt/XXV.3.204

Rubagumya, C. M. (2003). English medium primary schools in Tanzania: A new linguistic market in education? In B. Brock-Utne, M. Qorro, \& Z. Desai (Eds.), Language of Instruction in Tanzania and South Africa (LOITASA) (pp.149-169). Dar es Salaam: E\&D Limited.

Schachter, J. (1974). An error in error analysis .Language Learning, 24(2), 137-41. 
http://dx.doi.org/10.1111/j.1467-1770.1974.tb00502.x

Selinker, L. (1972). $\quad$ Interlanguage. $\quad I R A L \quad 10, \quad 209-31$. http://dx.doi.org/10.1515/iral.1972.10.1-4.209

Siraj-Blatchford, I., \& Clarke, P. (2000). Supporting identity, diversity and language in the early years, Open University Press, Bucks.

Snow, C. E., Burns, M. S., \& Griffin, P. (Eds.) (1998). Preventing reading difficulties in young children. Washington, DC: National Academy Press.

Stockwell, R., Bowen, J., \& Martin, J. (1965). The grammatical structures of English and Spanish. Chicago: University of Chicago Press.

Taylor, B. (1975). The use of over - generalization and transfer learning strategies by elementary and intermediate students in KSL. Language Learning, 25, 73-107. http://dx.doi.org/10.1111/j.1467-1770.1975.tb00110.x

Vygotsky, L. (1986). Thought and language.Cambridge, MIT Press, MA, USA.

Walter, C. W. (2007). First- to second-language reading comprehension: Not transfer, but access. International Journal of Applied Linguistics, 17(1), 19-35. http://dx.doi.org/10.1111/j.1473-4192.2007.00131.x

Wardaugh, R. (1970). The contrastive analysis hypothesis. TESOL Quarterly, 4(2). http://dx.doi.org/10.2307/3586182

Xiangying J. (2011). The role of first language literacy and second language proficiency in second language. Reading comprehension. The Reading Matrix, 11(2), 117-190.

\section{Copyright Disclaimer}

Copyright reserved by the author(s).

This article is an open-access article distributed under the terms and conditions of the Creative Commons Attribution license (http://creativecommons.org/licenses/by/3.0/). 